\title{
EFFICACY AND SAFETY OUTCOMES OF RIVAROXABAN IN ACUTE DEEP VENOUS THROMBOSIS PATIENTS
}

\section{BY}

Mustafa Soliman Abdelbary ${ }^{\mathrm{A}}$, Lamia Mohamed El Wakeel ${ }^{\mathrm{B}}$ and Neven Mohamed Sarhan ${ }^{\mathbf{C}}$

\section{FROM}

A. Professor of Vascular Surgery, Faculty of Medicine, Ain Shams University

B: Assistant Professor of Clinical Pharmacy, Faculty of Pharmacy, Ain Shams University

C: Teaching Assistant in Clinical Pharmacy department, Faculty of Pharmacy, Misr International University

\begin{abstract}
Background

Rivaroxaban is the first oral anticoagulant drug that is a direct inhibitor of activated factor X (FXa) of clotting which may provide a simple, fixed-dose regimen for treating acute deep-vein thrombosis (DVT) without the need for laboratory monitoring.
\end{abstract}

\section{Method}

An opened label randomized parallel group clinical trial compared subcutaneous enoxaparin $1 \mathrm{mg} / \mathrm{kg}$ once daily for 5 days followed by oral rivaroxaban $20 \mathrm{mg}$ once daily with subcutaneous enoxaparin $1 \mathrm{mg} / \mathrm{kg}$ once daily followed by a vitamin $\mathrm{K}$ antagonist (warfarin) for 2 month of treatment. The primary efficacy outcome for both was recurrent venous thromboembolism (VTE). The principal safety outcome was major bleeding or clinically relevant non major bleeding.

\section{Results}

Out of the 20 patients in the rivaroxaban group, 5 patients $(25 \%)$ developed bleeding events while in the standard therapy group 8 out of 20 patients, $40 \%$ developed bleeding events. Moreover, 10 patients in the rivaroxaban group $(50 \%)$ developed adverse drug reactions versus 14 patients (70\%) in the standard therapy group. However, none of the patients in both groups developed recurrent VTE neither DVT nor pulmonary embolism (PE).

\section{Conclusion}

Enoxaparin at dose of $1 \mathrm{mg} / \mathrm{kg}$ followed by rivaroxaban at a dose of $20 \mathrm{mg}$ once daily is effective, safe and well tolerated drug treatment option for patients with DVT.

\section{Introduction:}

Deep vein thrombosis (DVT) and acute pulmonary embolism (PE) are two manifestations of the same disorder, venous thromboembolism (VTE). Venous thromboembolism affects 1 to 2 adults per 1000 annually and is the third most common cause of vascular death after myocardial infarction and stroke (Oger, 2000). 
Although its exact incidence is unknown, nearly 1 million cases (incident or recurrent, fatal and nonfatal events) occur in the United States each year (Heit, 2008). Approximately 2 million patients are diagnosed with deep venous thrombosis (DVT) each year (Geerts et al., 2004). Even in the absence of pulmonary embolism (PE), DVT may cause significant morbidity resulting from chronic swelling, ulceration, debilitating pain, and future risk of recurrent DVT and PE (Hirsh and Hoak, 1996).

A thrombus in the deep venous system of the leg is not dangerous in itself. The situation becomes life-threatening when a piece of the blood clot breaks off travels downstream through the heart into the pulmonary circulation system, and becomes lodged in the lung. Diagnosis and treatment of DVT is meant to prevent pulmonary embolism (Goldhaber et al., 1999). Also post-phlebitic syndrome can occur after a deep vein thrombosis (the affected leg can become chronically swollen and painful with skin color changes and ulcer formation around the foot and ankle) (Kahn and Ginsberg, 2004). Given that VTE can be debilitating or fatal, it is important to treat it quickly and aggressively (Wells et al., 2000).

The current standard treatment for many patients with DVT is rapidly acting parenteral anticoagulants (low molecular weight heparin, unfractionated heparin or fondaparinux) for 5 to 7 days overlapped with at least 3 months of treatment with a vitamin K antagonist (warfarin) ( Guyatt et al., 2012).

Recently, a number of new oral and parenteral anticoagulants have been developed with the aim of overcoming some of the drawbacks of warfarin and the other currently available agents, and to improve the prevention and treatment of thromboembolic disorders. Rivaroxaban is the first oral anticoagulant drug that is a direct inhibitor of activated factor $\mathrm{X}(\mathrm{FXa})$ of clotting. This inhibition disrupts the intrinsic and extrinsic pathways of coagulation cascade, inhibiting therefore the formation of thrombin and thrombus formation. Rivaroxaban is well absorbed from the gut and maximum inhibition of factor Xa occurs four hours after a dose. The effects last 8-12 hours, but factor Xa activity does not return to normal within 24 hours so oncedaily dosing is possible ( Mueck et al., 2014).

Rivaroxaban demonstrated similar efficacy to warfarin for the treatment of acute VTE and prevention of recurrent VTE in large prospective randomized controlled trials (Bauersachs et al., 2010; Buller et al., 2012). These studies demonstrate that oral rivaroxaban has similar efficacy to conventional anticoagulation as a primary therapy for DVT and PE, without an increased risk of bleeding. Therefore, the aim of the present study was to compare efficacy and safety of enoxaparin / rivaroxaban versus standard therapy on management of patients with acute DVT.

\section{Study Design}

This study was an opened label randomized parallel group clinical trial. The study was conducted at Ain Shams University Hospitals (ASUH) Vascular surgery department from June 2012 till December 2013.

\section{Patients}

All patients presenting to the department of vascular surgery at ASUHs and diagnosed with acute DVT were assessed for eligibility criteria. Patients were eligible if they were in the age range from 18 to 65 and recently diagnosed with lower extremity DVT by 
Duplex. Patients were ineligible to participate if they had renal disorder, clinically hepatic disorder and clinically significant active bleeding.

Patients who fulfilled the inclusion criteria were included and randomized to one of two groups; the first group was of twenty patients who received enoxaparin $1 \mathrm{mg} / \mathrm{Kg}$ by subcutaneous injection for at least 5 days in conjunction with dose adjusted oral warfarin. Once the target INR was reached enoxaparin was discontinued and the patients continued on dose adjusted oral warfarin once daily for two months while the second group was of twenty patients who received enoxaparin $1 \mathrm{mg} / \mathrm{Kg}$ by subcutaneous injection for at least 5 days followed by oral rivaroxaban at a fixed dose of $20 \mathrm{mg}$ once daily for two months.

\section{Ethical Consideration:}

A written informed consent was obtained from each of the participants before recruitment in the study. Patients who refused to sign the informed consent were excluded from this study. The study design was approved by the local Ethics Committee Review Board at Faculty of Pharmacy, Ain Shams University, Egypt.

\section{Methods:}

All patients were assessed at baseline by the physician and the clinical pharmacist for full medical history including their age, sex, co-morbid diseases and risk factors of DVT, medication history and clinical assessment. Clinical pharmacist assessed patients weekly for two months for efficacy outcomes including incidence and severity of thromboembolic complications such as recurrent DVT or PE and safety outcomes including incidence and severity of bleeding episodes (major or minor). Moreover patients were assessed for other adverse drug reactions to the use of rivaroxaban or warfarin such as diarrhea, constipation, nausea, heart burn, dizziness, vomiting, back pain, abdominal pain, edema, headache, rash, fever, pain, hypotension and night sweating.

\section{Statistical analysis:}

Data were collected, revised, verified then edited on personal computer. Statistical analysis was performed using SPSS software (statistical package for the social sciences, version 21, SPSS Inc., Chicago, IL, USA). Numerical data were summarized using means and standard deviations or medians and ranges. Categorical data were summarized as percentages. Data were explored for normality using Kolmogrov-Smirnov test and Shapiro-Wilk test.

\section{Results}

\section{Safety and Efficacy outcomes}

Patient demographics \& clinical characteristics were comparable in both groups except for gender and white blood cells (WBCs) as shown in table (1). 
Table 1: demographic data \& Clinical characteristics

\begin{tabular}{|l|l|l|l|}
\hline Characteristic & $\begin{array}{l}\text { Rivaroxaban } \\
(\mathbf{N = 2 0})\end{array}$ & $\begin{array}{l}\text { Standard } \\
(\mathbf{N}=\mathbf{2 0})\end{array}$ & $\begin{array}{l}\text { P- } \\
\text { value }\end{array}$ \\
\hline Male Sex & $14(70 \%)$ & $7(35 \%)$ & 0.027 \\
\hline Age (Yrs), mean \pm SD & $50.90 \pm 9.23$ & $49.00 \pm 10.29$ & \\
\hline Complete Blood count as mean \pm SD & & & \\
\hline Red blood cells (RBCs) & $4.42 \pm 0.67$ & $4.52 \pm 0.43$ & 0.396 \\
\hline Hemoglobin & $12.62 \pm 2.24$ & $12.33 \pm 1.58$ & 0.285 \\
\hline Hematocrit & $39.23 \pm 5.70$ & $37.15 \pm 5.32$ & 0.046 \\
\hline MCV & $88.75 \pm 6.77$ & $83.28 \pm 6.82$ & 0.117 \\
\hline MCH & $28.09 \pm 2.96$ & $28.56 \pm 3.27$ & 0.812 \\
\hline MCHC & $31.95 \pm 2.39$ & $32.60 \pm 1.71$ & 0.403 \\
\hline White blood cells (WBCs) & $7.25 \pm 1.54$ & $9.15 \pm 2.60$ & 0.016 \\
\hline Platelets Median & 278.5 & 298 & $\begin{array}{l}\text { P } \\
\text { Interquartile range }\end{array}(174.00445 .00)$ \\
\hline
\end{tabular}

Out of the 20 patients in the rivaroxaban group, 5 patients $(25 \%)$ developed bleeding events while in the standard therapy group 8 out of 20 patients, $40 \%$ developed bleeding events. The overall bleeding incidence was numerically lower; but not significantly lower $(\mathrm{P}=0.311)$ in patients receiving rivaroxaban than those receiving standard therapy as shown in Figure (1).

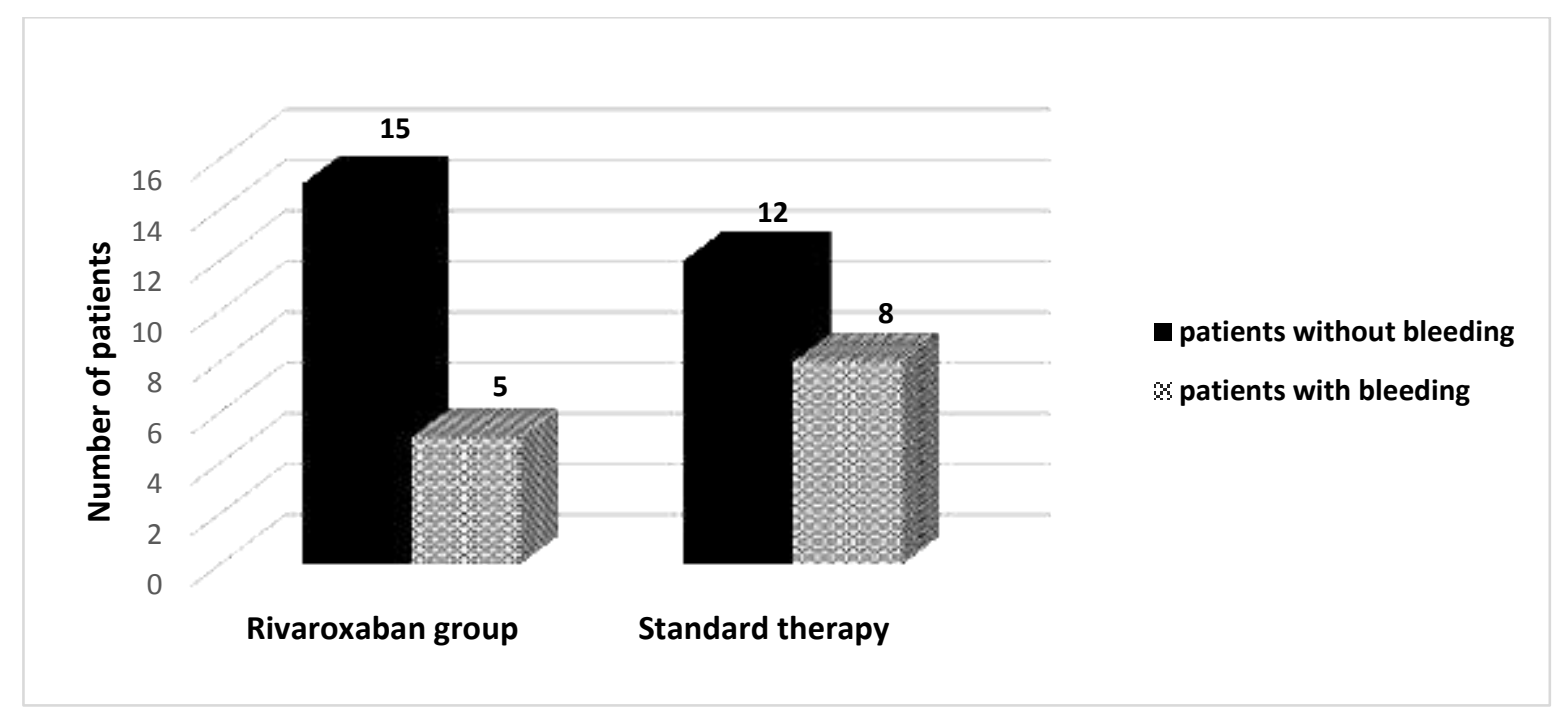

Figure 1: Overall bleeding incidence in Rivaroxaban group versus Standard therapy group 
Moreover, 10 patients in the rivaroxaban group (50\%) developed adverse drug reactions versus 14 patients $(70 \%)$ in the standard therapy group. Therefore, the overall incidence of ADRs was numerically lower; but not significantly lower $(P$ value $=0.197)$ in patients receiving rivaroxaban than those receiving standard therapy as shown in Figure (2).

\section{Laboratory evaluation}

After 8 weeks of follow up there was no significant difference between rivaroxaban group and standard therapy group in blood profile including RBCs count, hemoglobin, hematocrit, mean corpuscular volume, mean corpuscular hemoglobin, mean corpuscular hemoglobin concentration, platelets count and WBCs count as shown in table (2).

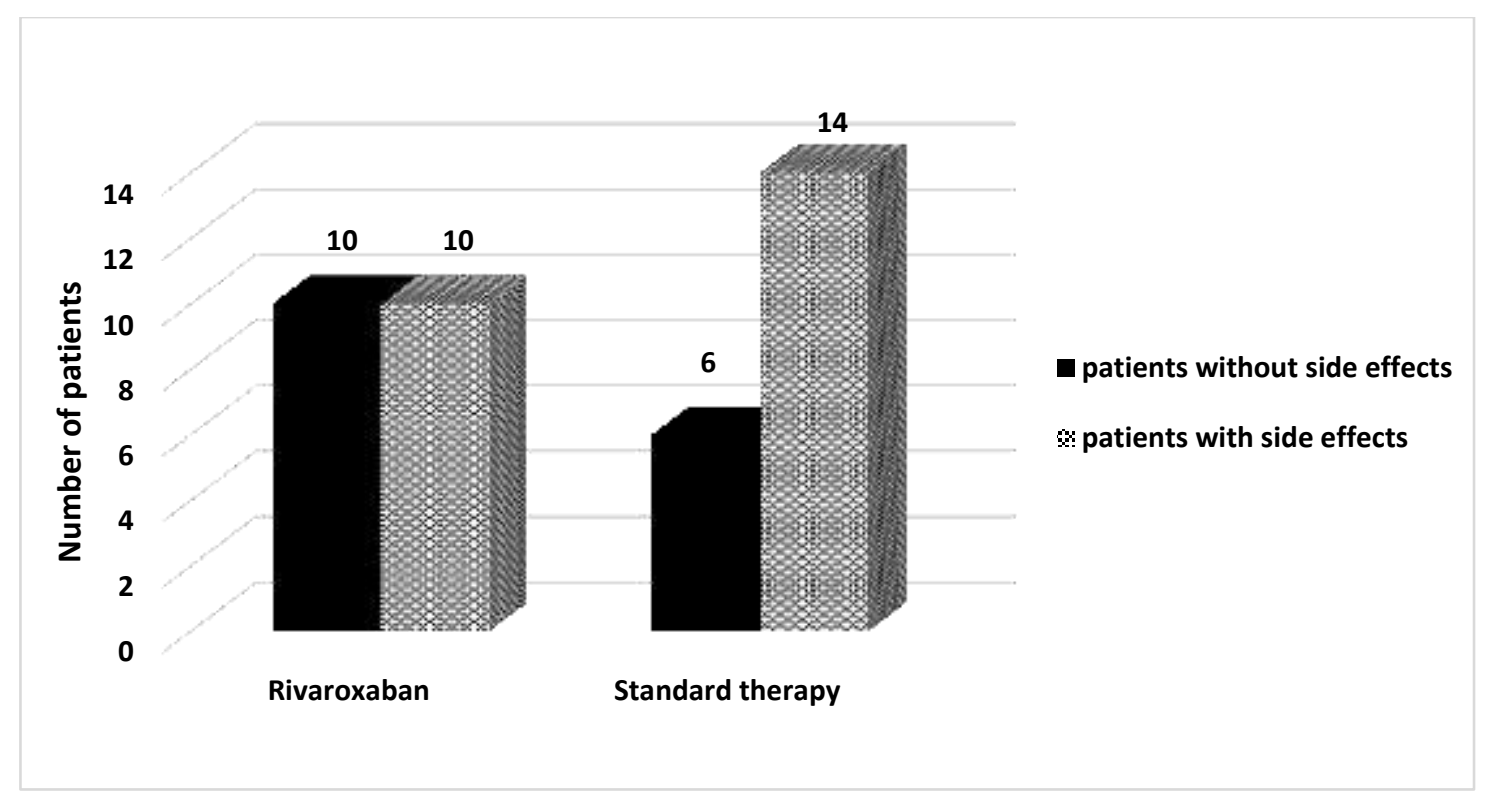

Figure 2: Overall adverse drug reactions (ADRs) incidence in Rivaroxaban group versus Standard therapy group

However, none of the patients in both groups developed recurrent VTE neither DVT nor PE. The overall incidences of recurrent VTE were similar in patients receiving rivaroxaban and those receiving standard therapy. 
Table 2: Laboratory evaluation after 8 weeks

$\begin{array}{llll}\begin{array}{lll}\text { Characteristic } \\ \text { Complete Blood count as mean } \pm \\ \text { SD }\end{array} & \begin{array}{l}\text { Sivaroxaban } \\ \mathbf{( N = 2 0 )}\end{array} & \begin{array}{l}\text { Standard } \\ \text { Therapy } \\ \mathbf{N = 2 0}\end{array} & \text { P-value } \\ \quad \text { Red blood cells (RBCs) } & 4.70 \pm 0.46 & 4.52 \pm 0.43 & 0.237 \\ \quad \text { Hemoglobin } & 13.21 \pm 1.97 & 12.71 \pm 1.74 & 0.059 \\ \text { Hematocrit } & 40.91 \pm 3.88 & 38.66 \pm 4.11 & 0.102 \\ \text { MCV } & 87.55 \pm 6.94 & 85.74 \pm 5.25 & 0.131 \\ \text { MCH } & 28.19 \pm 3.38 & 28.25 \pm 2.76 & 0.686 \\ \text { MCHC } & 32.19 \pm 3.24 & 32.91 \pm 1.85 & 0.652 \\ \quad \text { White blood cells (WBCs) } & 7.69 \pm 1.73 & 9.30 \pm 3.0 & 0.38 \\ \text { Platelets Median } & 276 & 287 & \mathrm{P}= \\ \text { Interquartile range } & (173.00-445.00) & (126.00-428.00) & 0.807\end{array}$

\section{Discussion}

According to guidelines published by American Collage of Chest Physicians (ACCP) the current standard treatment for many patients with DVT is rapidly acting parenteral anticoagulants (low molecular weight heparin, unfractionated heparin or fondaparinux) for 5 to 7 days overlapping with a vitamin $\mathrm{K}$ antagonist (warfarin) for at least 3 months of treatment (Kearon et al., 2012). In 2012 the FDA approved rivaroxaban for the treatment of acute DVT. The present study shows that rivaroxaban is as effective as standard therapy, with similar safety, for the treatment of acute DVT. The overall incidences of recurrent VTE and bleeding events were similar in patients receiving rivaroxaban and those receiving standard therapy. In agreement with Agnelli, et al. study which showed that oral rivaroxaban at a dose of $15 \mathrm{mg}$ twice daily for 3 weeks followed by $20 \mathrm{mg}$ once daily for 3 month has non-inferior and possibly superior efficacy and similar safety profile in terms of major and non-major bleeding compared to standard therapy in the treatment of patients with acute deep venous thrombosis. Moreover, Eriksson, et al. 2008 and Lassen, et al. 2008 showed that oral rivaroxaban $(10 \mathrm{mg})$ once daily has non-inferior and possibly superior efficacy compared to subcutaneous enoxaparin $40 \mathrm{mg}$ once daily with similar safety profiles including low rates of major bleeding in preventing VTE in adult patients undergoing total hip or knee replacement surgery. However, Cohen, et al. 2013 showed that taking rivaroxaban 10 $\mathrm{mg}$ once daily for 35 days was associated with a significant increase bleeding rates, compared with standard 10-day treatment with enoxaparin $40 \mathrm{mg}$ by subcutaneous injection, in acutely ill medical patients.

\section{Conclusion:}

No notable differences were found during the 2 month of follow up regarding the incidence of subsequent recurrent VTE, bleeding and adverse drug reactions in patients treated with rivaroxaban than those receiving standard therapy. In conclusion, 
the present study showed that rivaroxaban at a dose of $20 \mathrm{mg}$ once daily is effective, safe and well tolerated drug treatment option for patients with DVT.

\section{Recommendations:}

Future studies should be conducted for a longer duration to assess the long-term efficacy, safety and coagulation profile changes of rivaroxaban in deep venous thrombosis patients. Finally, more data are required on the optimal management of major bleeding events and on the management of patients requiring urgent invasive procedures.

\section{References:}

Agnelli, G., Berkowitz, S., Bounameaux, H., Büller, H., Cohen, A., Gallus, A and Spadari, G. (2010). “ Oral rivaroxaban for symptomatic venous thromboembolism. “N Engl J Med, 363

Bauersachs R, Berkowitz S.D, Brenner B, et al. (2010). "Oral rivaroxaban for symptomatic venous thromboembolism." N Engl J Med 363(26): 2499-2510.

Buller H.R., Prins M.H., Lensin A.W., et al. (2012). "Oral rivaroxaban for the treatment of symptomatic pulmonary embolism." N Engl J Med 366(14): 1287-1297.

Cohen, A. T., Spiro, T. E., Büller, H. R., Haskell, L., Hu, D., Hull, R and Tapson, V. (2013). Rivaroxaban for thromboprophylaxis in acutely ill medical patients. N Engl J Med 368(6), 513-523

Eriksson, B. I., Borris, L. C., Friedman, R. J., Haas, S., Huisman, M. V., Kakkar, A. K.and Geerts, W. (2008). Rivaroxaban versus enoxaparin for thromboprophylaxis after hip arthroplasty. N Engl J Med 358(26), 2765-2775.

Geerts, W. H., Pineo G. F., Heit J.A., Bergqvist D., Lassen M.R., Colwell C.W., Ray J.G. (2004). "Prevention of venous thromboembolism: the Seventh ACCP Conference on Antithrombotic and Thrombolytic Therapy." Chest 126(3 Suppl): 338S-400S.

Goldhaber, S. Z., Visani L and De Rosa M. (1999). "Acute pulmonary embolism: clinical outcomes in the International Cooperative Pulmonary Embolism Registry (ICOPER)." Lancet 353(9162): 1386-1389.

Guyatt, G. H., Akl E. A., Crowther M., Gutterman D.D. and Schuunemann (2012). "Executive summary: Antithrombotic Therapy and Prevention of Thrombosis, 9th ed: American College of Chest Physicians Evidence-Based Clinical Practice Guidelines." Chest 141(2 Suppl): 7S-47S.

Heit, J. A. (2008). "The epidemiology of venous thromboembolism in the community." Arterioscler Thromb Vasc Biol 28(3): 370-372.

Hirsh, J. and Hoak J. (1996). "Management of deep vein thrombosis and pulmonary embolism. A statement for healthcare professionals. Council on Thrombosis (in consultation with the Council on Cardiovascular Radiology), American Heart Association." Circulation 93(12): 2212-2245.

Kahn, S. R. and Ginsberg J. S. (2004). "Relationship between deep venous thrombosis and the postthrombotic syndrome." Arch Intern Med 164(1): 17-26.

Kearon, C., Akl E. A., Comerota A.J., et al. (2012). "Antithrombotic therapy for VTE disease: Antithrombotic Therapy and Prevention of Thrombosis, 9th ed: American 
College of Chest Physicians Evidence-Based Clinical Practice Guidelines." Chest 141(2 Suppl): e419S-494S.

Lassen, M. R., Ageno, W., Borris, L. C., Lieberman, J. R., Rosencher, N., Bandel, T. J. and Turpie, A. G. (2008). " Rivaroxaban versus enoxaparin for thromboprophylaxis after total knee arthroplasty." N Engl J Med 358 (26), 27762786.

Mueck, W., Stampfuss, J., Kubitza, D., \& Becka, M. (2014)." Clinical pharmacokinetic and pharmacodynamic profile of rivaroxaban" . Clin pharmacokinet 53(1), 1-16.

Oger, E. (2000). "Incidence of venous thromboembolism: a community-based study in Western France. EPI-GETBP Study Group. Groupe d'Etude de la Thrombose de Bretagne Occidentale." Thromb Haemost 83(5): 657-660.

Wells, P. S., Anderson D. R. and Ginsberg J. (2000). "Assessment of deep vein thrombosis or pulmonary embolism by the combined use of clinical model and noninvasive diagnostic tests." Semin Thromb Hemost 26(6): 643-656. 


\section{الملخص العربي \\ فاعلية و سلامة عقار الريفاروكسابان في مرضى التجلط الوريدي العميق المزمن \\ للسادة الاكاترة

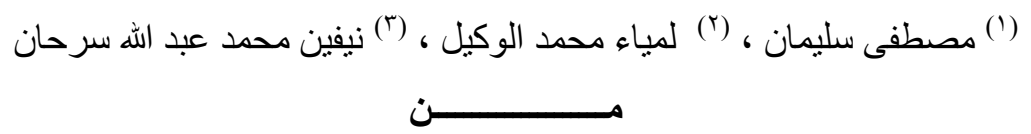

(') أستاذ جر احة الأو عبة الدموية كلية الطب - جامعة عين شمس (r) أستاذ مساعد الصيدلة الإكلينيكي

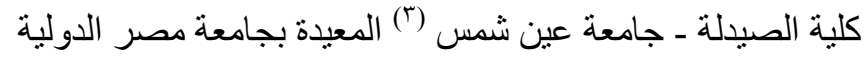

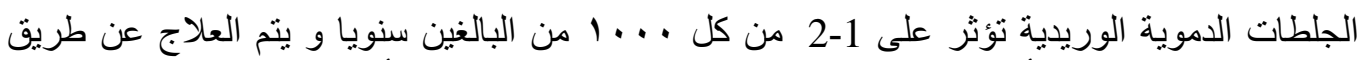

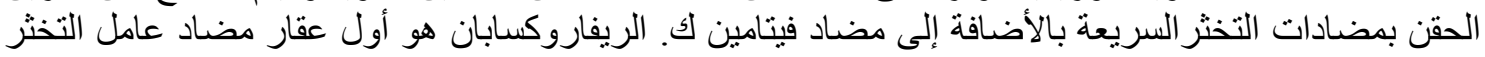
عن طريق الفم . Xa

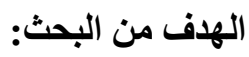

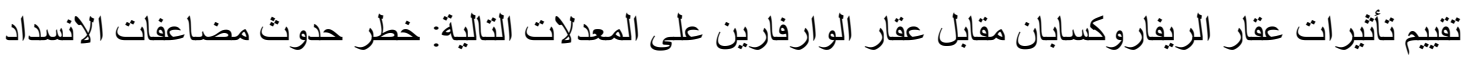

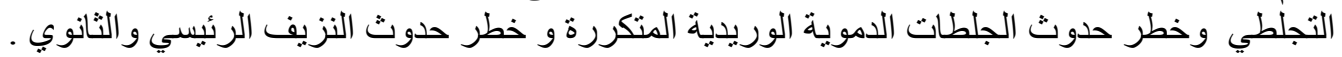

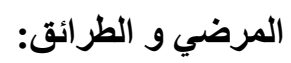

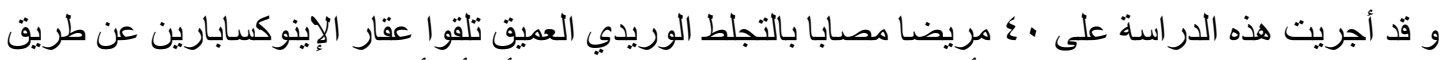

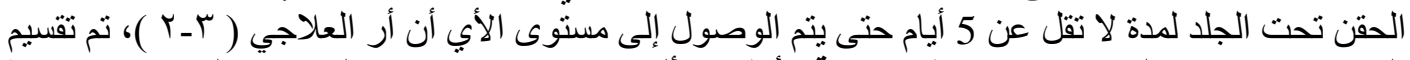

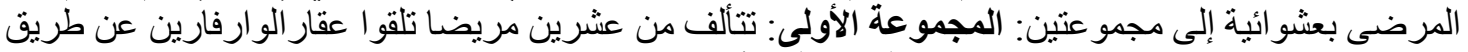

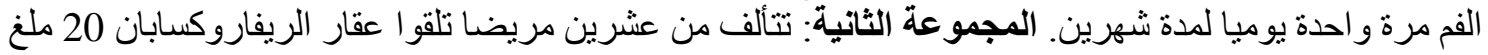
عن طريق الفم مرة واحدة بورة يوميا لمدة شهرين. النتائج :

أظهرت الدر اسة أن المعدل العام من الجلطات الدموية الوريدية المتكررة مماثل في كلتا المجمو عتين. كما أنه لا لا

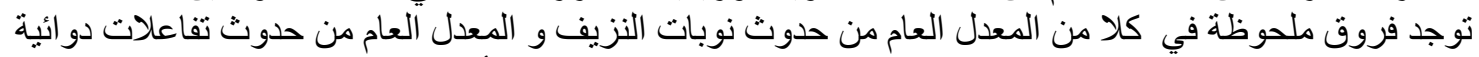

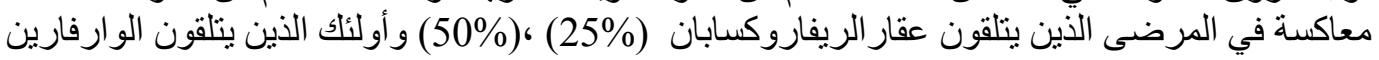

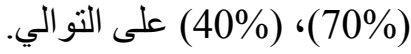

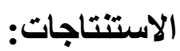

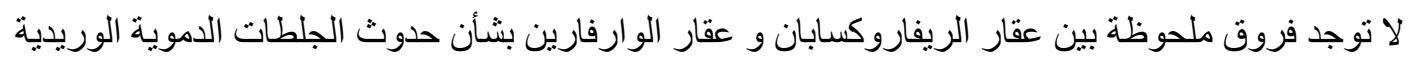

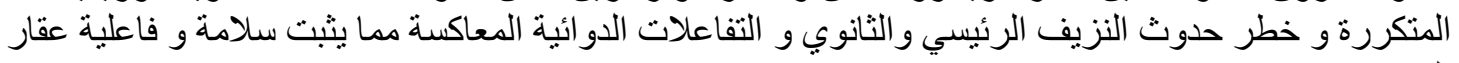

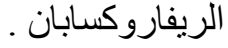

